\title{
Por onde quero ir? Interesses pessoais na escolha de um trajeto urbano
}

\author{
Ana Paula Chaves ${ }^{1}$, Igor Steinmacher ${ }^{1}$, Marco Aurélio Gerosa ${ }^{2}$ \\ ${ }^{1}$ Departamento Acadêmico de Computação (DACOM) \\ Universidade Tecnológica Federal do Paraná - Câmpus Campo Mourão (UTFPR-CM) \\ Caixa Postal: 271 - 87301-899 - Campo Mourão - PR - Brasil \\ ${ }^{2}$ Instituto de Matemática e Estatística - Universidade de São Paulo (IME-USP) \\ Rua do Matão, 1010 - 05508-090 - São Paulo - SP - Brasil \\ \{anachaves,igorfs\} @utfpr.edu.br, gerosadime.usp.br
}

\begin{abstract}
When moving throughout the city, people may have different interests. Previous researches have considered user preferences to recommend paths and destinations. However, these preferences are generally related to time, distance and cost. In this paper, we assume that other personal and social interests can influence the path choice and should be considered in customized recommendation systems. Thus, this paper presents an exploratory study aiming to analyze what people consider as their interest while choosing the path. We conducted interviews and qualitatively analyzed the data by using open and axial coding. Our results evidenced that people have different interests in different contexts and aspects that influence the choice range from the landscape to the opinion of acquaintances about the path.
\end{abstract}

Resumo. Quando se deslocam pelas cidades, as pessoas podem ter diferentes interesses. Pesquisas tem se preocupado em considerar as preferências dos usuários para fazer recomendações de trajetos e destinos. Entretanto, essas preferências são, em geral, relacionadas a tempo, distância e custo do trajeto. Este artigo considera que outros interesses pessoais e sociais podem ter impacto na escolha do trajeto e que, portanto, deveriam ser considerados em sistemas de recomendação personalizada. Para isso, o artigo apresenta uma pesquisa exploratória que analisa o que as pessoas consideram como seu interesse no momento da escolha do trajeto. Foram realizadas entrevistas e os dados qualitativos coletados foram analisados utilizando codificação aberta e axial. Os resultados evidenciam que as pessoas têm diferentes interesses em contextos diferentes e que os aspectos que podem influenciar a escolha vão desde a paisagem até a opinião de pessoas conhecidas sobre o trajeto.

\section{Introdução}

Sistemas georreferenciados fazem parte da vida das pessoas. A popularização da tecnologia de GPSs (Global Positioning Systems), o uso de mapas digitais e sistemas de recomendação reduziu o esforço necessário para escolher seus trajetos [Ballatore and Bertolotto 2015]. A ampla utilização de aplicativos como Waze ${ }^{1}$ e Google Maps ${ }^{2}$

\footnotetext{
${ }^{1}$ https://www.waze.com

${ }^{2}$ https://maps.google.com
} 
mostra que as pessoas têm interesse em buscar por melhores trajetos, tanto no seu dia-adia quanto em situações não rotineiras.

Entretanto, pessoas têm diferentes interesses quando trafegam pelas cidades, o que traz a preocupação em gerar mapas diferentes para cada pessoa, com base no perfil do usuário [Ballatore and Bertolotto 2015][Campigotto et al. 2016]. Recentemente, pesquisadores têm se preocupado em considerar fatores como restrições do local (origem, destino, pontos de interesse etc.), restrições de tempo e preferências do usuário para oferecer recomendações de trajeto personalizadas [Chen et al. 2015]. Esses trabalhos, em geral, consideram como interesse elementos variados, relacionados às condições de trânsito e das vias, por exemplo, distância, tempo, custo, tráfego, consumo de combustível, entre outros [Campigotto et al. 2016].

Pesquisas voltadas para recomendação em redes sociais baseadas em localização (LBSN - Location-Based Social Networks) tendem a considerar informações do perfil social do usuário (por exemplo, utilizando algoritmos de filtragem colaborativa) e seu contexto estático (idade, gênero, profissão, histórico de locais visitados). Bao et al. (2012) utilizam opiniões de "experts locais" sobre pontos de interesse. Contudo, esses trabalhos ainda têm pouco enfoque no contexto dinâmico, que incluem localização atual do usuário, humor, a atividade que está realizando no momento (por exemplo, em férias ou no trabalho) e condições ambientais (como condições climáticas e relevo) [Bao et al. 2015]. Além disso, pessoas podem possuir outros tipos de preferências que influenciem na escolha do trajeto, que dizem respeito a características individuais e sociais, como paisagens que gostam de ver, lugares que gostam de frequentar, pontos de interesse que gostariam de conhecer, pessoas com quem gostariam de interagir, entre outros. Esses fatores têm sido recentemente explorados para recomendação de lugares para visitação (especialmente voltados para turistas) [Chen et al. 2015; Kurashima et al. 2012; Pires et al. 2015], mas ainda são desconsiderados pelos algoritmos de recomendação de rotas. Ademais, as pesquisas não discutem sobre quais interesses poderiam influenciar a escolha menos óbvia de um trajeto, por exemplo, um trajeto mais longo ou mais demorado.

Diante deste cenário, esta pesquisa se concentra em identificar evidências empíricas de quais tipos de preferências afetam a escolha do trajeto e em que contexto elas são relevantes, respondendo à questão "O que as pessoas consideram interessante para a escolha do trajeto durante o deslocamento urbano?". Para isso, o objetivo deste artigo é apresentar os resultados de uma entrevista realizada com sete sujeitos sobre seu perfil de deslocamento em trajetos rotineiros e não rotineiros. Os tipos de deslocamento foram divididos em rotineiros e não rotineiros por partir do pressuposto de que pessoas em atividades do seu dia-a-dia têm interesses diferentes na escolha do trajeto em relação a pessoas em atividades esporádicas. No contexto desta pesquisa, por perfil de deslocamento entendem-se as razões que levam os indivíduos a se locomoverem e a forma como escolhem seus trajetos. Para os trajetos rotineiros, foram consideradas quaisquer atividades que o indivíduo faz constantemente no seu dia-a-dia, ainda que não ocorram com frequência ou horários pré-determinados. Por exemplo, ir ao mercado é considerado como uma atividade rotineira, apesar de não acontecer diariamente e não ter um dia ou horário pré-definido. Para os trajetos não rotineiros, foram consideradas atividades imprevistas e/ou esporádicas, realizadas fora do contexto diário. Por exemplo, atividades realizadas durante o período de férias ou fins de semana, viagens esporádicas a trabalho ou turismo, entre outras. Os dados qualitativos coletados nas 
entrevistas foram analisados utilizando técnicas de codificação aberta e axial [Corbin and Strauss 2014]. Os resultados destacam as diferenças de perfil de deslocamento para um mesmo indivíduo, quando em situações rotineiras ou não rotineiras, e que as características que podem influenciar vão desde as paisagens existentes no caminho até a opinião de conhecidos sobre o trajeto. Como contribuição, espera-se que este resultado forneça subsídios para novas pesquisas que objetivem a criação de modelos, métodos e processos para o desenvolvimento de sistemas de recomendação personalizada, que considerem a influência dos interesses pessoais e sociais para a escolha do trajeto.

\section{Trabalhos relacionados}

No deslocamento urbano, distância de um trajeto e o tempo de chegada até o destino são aspectos importantes para a escolha de um trajeto [Yang et al. 2015]. Entretanto, pesquisadores já se atentaram para o fato de que pessoas possuem diferentes preferências que influenciam essa escolha [Ballatore and Bertolotto 2015]. Yang et al (2015) afirma que o serviço de roteamento deveria apoiar mais que um critério e capturar as incertezas, incorporando as preferências e o contexto dos usuários.

De acordo com Adomavicius e Tuzhilin (2011), as abordagens para usar informações contextuais para recomendação podem ser divididas em dois grupos: pela pesquisa solicitada pelo usuário do trajeto ou pelas suas preferências informadas ou inferidas. Os contextos usualmente analisados são direcionados a horários locais, condições climáticas ou localização [Adomavicius and Tuzhilin 2011]. Os critérios elegidos como preferências em geral são relacionados à distância do trajeto, tempo de viagem, consumo de combustível, custos com pedágios, quantidade de semáforos [Yang et al. 2015]. De maneira geral, os trabalhos sugerem que o usuário tenha autonomia para decidir quais desses elementos tem mais impacto na sua escolha do trajeto para, então, recomendar a rota mais próxima da necessidade do usuário. Especificamente para congestionamentos, os trabalhos são destinados a sugerir alterações no trajeto, com base na análise dinâmica do fluxo de trânsito [Pires et al. 2015].

Sistemas para planejamento de viagens utilizam preferências por lugares e popularidade de pontos de interesse, obtidos a partir de fontes como redes sociais baseadas em localização (Location-Based Social Networks), georreferenciamento de fotos e histórico de viagens [Chen et al. 2015; Kurashima et al. 2012], e até mesmo a opinião de outros indivíduos sobre os pontos de interesses [Bao et al. 2012; Su et al. 2014]. Outros trabalhos sugerem o uso de sensores como RFID para monitorar o comportamento dos turistas e sugerir otimização de trajetos [Tsai and Lai 2013; Tsai and Chung 2012].

Entretanto, na literatura, há pouco conhecimento sobre as razões que levam as pessoas a elegerem um ou outro trajeto, a despeito do tempo, distância e custo. AbouZeid et al. (2008) sugerem que pessoas precisam de opções para que reflitam sobre a felicidade do trajeto que realizam. Existem poucas evidências que dizem quais interesses pessoais influenciam na escolha menos óbvia de um trajeto.

\section{Método de Pesquisa}

Foram realizadas entrevistas com indivíduos a respeito do seu padrão de deslocamento em situações rotineiras e não rotineiras. Foram entrevistados homens e mulheres, com idades entre 18 e 62 anos e com diferentes profissões (agente de viagens, engenheiro, 
estudante, servidor de instituição pública, professor, aposentado). Além disso, são oriundas de cidades pequenas, médias e grandes, nos estados do Paraná e São Paulo. A escolha dos entrevistados foi realizada por conveniência, buscando por pessoas que se adequassem ao perfil desejado, garantindo que todas as características mencionadas acima estariam igualmente representadas. As entrevistas foram realizadas online, por voz, gravadas ${ }^{3}$ e transcritas.

Inicialmente, os entrevistados foram informados sobre a questão de pesquisa " $O$ que você considera interessante para a escolha do trajeto durante o deslocamento urbano?". Em seguida, foi apresentado o conceito esperado de trajetos rotineiros. As pessoas foram convidadas a imaginar o seu contexto diário para responder às questões. Após a primeira rodada de perguntas, o mesmo processo foi utilizado para trajetos não rotineiros. As questões respondidas em ambas as rodadas foram:

- Por que você se desloca?

- Como você se desloca?

- Como você escolhe o trajeto?

- O que te leva/levaria a fazer trajetos diferentes?

- Como você escolhe o seu modo de viagem?

- Você conhece/procura conhecer os arredores do seu destino?

- O que te leva/levaria a conhecer?

A seguir, serão apresentados os procedimentos de utilizados para a análise qualitativa das entrevistas.

\subsection{Análise qualitativa}

Após a transcrição das entrevistas, foram executadas as técnicas de codificação aberta e axial propostas por Corbin e Strauss (2014) para o método Grounded Theory. A codificação aberta consiste em atribuir um código substantivo ao dado, compará-lo com outros dados e designá-lo em categorias e/ou subcategorias. A codificação axial consiste na formação e desenvolvimento de um conceito, auxiliando o pesquisador a realizar a integração das categorias geradas a partir da codificação aberta, elaborando conexões entre as categorias e as sub-categorias [Cassiani et al. 1996].

Corbin e Strauss (2014) propuseram também a codificação seletiva, que é a busca pelo fenômeno central que define todas as categorias para formar a teoria fundamentada nos próprios dados. Entretanto, para o propósito desta pesquisa, as fases aberta e axial foram suficientes para responder a questão de pesquisa.

As entrevistas foram analisadas em duas etapas. Cada etapa envolveu as respostas de uma rodada de perguntas (trajetos rotineiros e não rotineiros). Os códigos foram criados a partir dos textos das entrevistas, baseados na percepção dos pesquisadores. Categorias foram utilizadas para agrupar códigos referentes a um mesmo significado conceitual. Durante a análise, conforme aumentava a interação com os dados, as categorias e subcategorias evoluíam a fim de aumentar a clareza dos conceitos. Os resultados dessa análise são apresentados na Seção 4 deste artigo.

\footnotetext{
${ }^{3}$ As gravações foram previamente autorizadas pelos respondentes.
} 
A etapa de codificação axial foi realizada alternadamente à codificação aberta, em um processo iterativo. Entretanto, ao final da codificação aberta, todas as relações entre categorias foram revisadas e refinadas.

\section{Resultados}

Para facilitar a apresentação dos conceitos, esta seção está dividida em: Trajetos não rotineiros e Trajetos rotineiros. Os Trajetos não rotineiros são divididos em Trajetos a trabalho e Trajetos a lazer. Essa subdivisão emergiu da análise, visto que pessoas em trajetos não rotineiros possuem perfis de deslocamento diferentes de acordo com o objetivo da atividade (trabalho ou lazer). Isso pode ser claramente observado na citação "É melhor pegar um exemplo especifico, né, porque muda. Se for a trabalho é uma coisa, se for em férias é totalmente diferente" [E1]. Essa diferença se manifesta nas diversas categorias, desde o modo de deslocamento (meio de transporte) até a flexibilidade em conhecer os arredores do destino.

As demais categorias discutidas a seguir são: Motivo de deslocamento; Meio de transporte e Critério para escolha do meio de transporte; Características importantes do trajeto; Critério para escolha do caminho e Flexibilidade do trajeto; e Flexibilidade para conhecer os arredores.

\subsection{Trajetos não rotineiros}

As Tabelas 1 e 2 apresentam as categorias, subcategorias e códigos identificados para Trajetos não rotineiros a trabalho e para Trajetos não rotineiros a lazer, respectivamente. A análise dos dados sobre trajetos não rotineiros mostrou que o principal motivo desse tipo de deslocamento são as Atividades de lazer, Atividades profissionais e Atividades pessoais que acontecem esporadicamente. Para cada um desses contextos, o perfil de deslocamento e as características importantes do trajeto foram divergentes, $\mathrm{o}$ que destaca a relevância da atividade do indivíduo como fator de influência para a definição de seus interesses no trajeto.

Tabela 1. Categorias, subcategorias e códigos identificados para Trajetos não rotineiros a trabalho.

\begin{tabular}{|c|c|c|}
\hline Categoria & Subcategoria & Códigos \\
\hline \multirow{2}{*}{ Motivo do deslocamento } & Atividades profissionais & Trabalho, Estudo, Compromissos, \\
\hline & Atividades pessoais & Alimentação, Necessidade/obrigação, Comércio, \\
\hline Meio de transporte & - & Táxi, A pé, Carro pessoal, Avião, Bicicleta \\
\hline $\begin{array}{c}\text { Critério para escolha do } \\
\text { meio de transporte }\end{array}$ & - & Custo, Saúde, Distância, tempo \\
\hline \multirow{2}{*}{$\begin{array}{l}\text { Características } \\
\text { importantes do trajeto }\end{array}$} & Características da via & $\begin{array}{l}\text { Trajetos fáceis, Trajetos não cansativos, Distância, Fluxo de } \\
\text { Trânsito, Segurança, Condições de rodovias }\end{array}$ \\
\hline & Características do local & $\begin{array}{l}\text { Comércio, Atrações turísticas, Características/cultura locais, } \\
\text { Coisas diferentes, Conhecer lugares novos, }\end{array}$ \\
\hline \multirow{2}{*}{$\begin{array}{l}\text { Critérios para escolha do } \\
\text { caminho }\end{array}$} & Segurança & Caminho mais movimentado \\
\hline & Características do local & Conhecer lugares novos \\
\hline \multirow{3}{*}{$\begin{array}{c}\text { Flexibilidade para } \\
\text { conhecer os arredores }\end{array}$} & Oportunidade & Alimentação, Explorar os arredores do hotel \\
\hline & Tempo & Tempo \\
\hline & - & Desinteresse por locais familiares \\
\hline
\end{tabular}


Tabela 2: Categorias, subcategorias e códigos identificados para Trajetos não rotineiros a lazer.

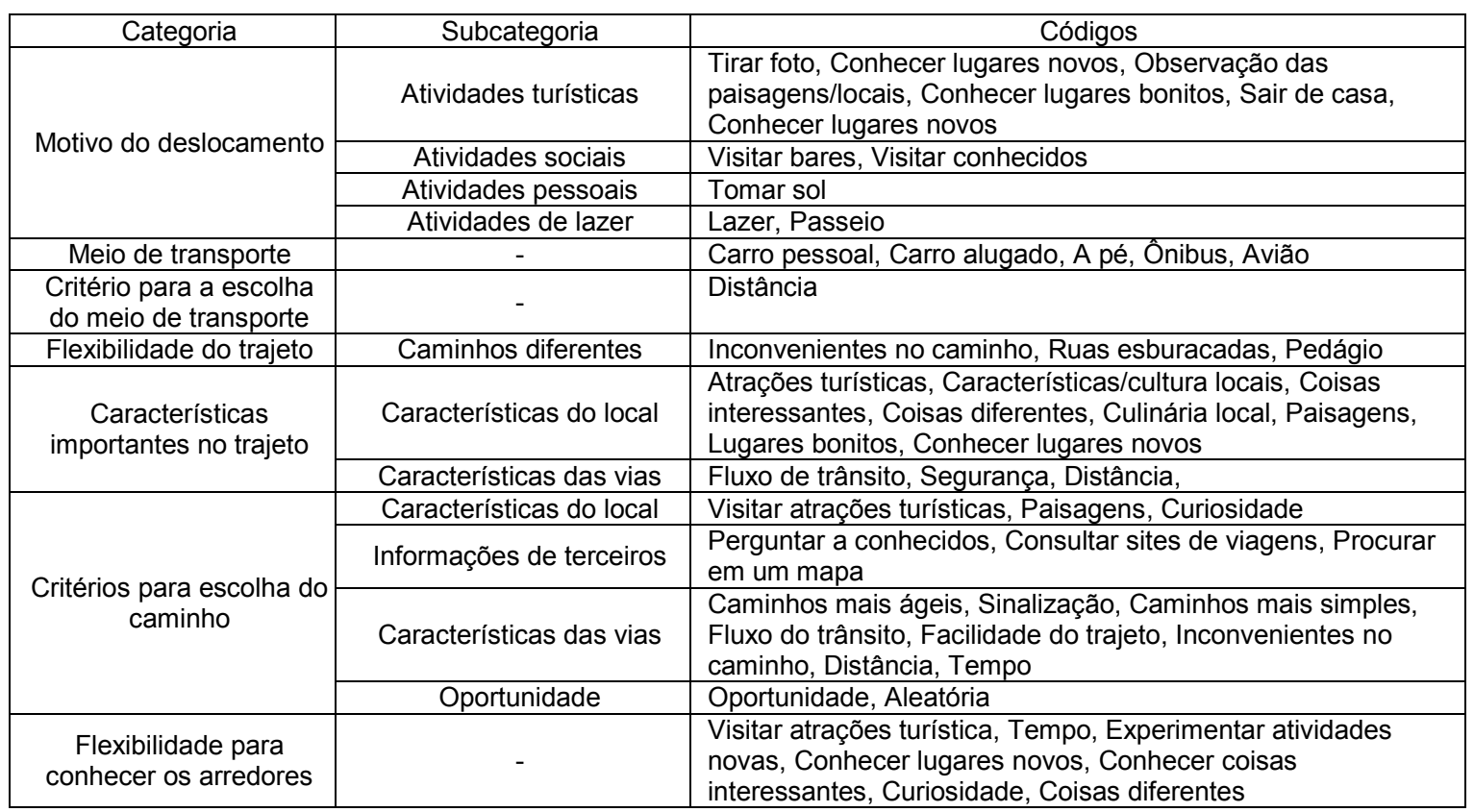

Quando direcionado às Características importantes do trajeto, a análise mostrou que as pessoas em Trajetos a lazer consideram importante Visitar atrações turísticas, Paisagens, Conhecer lugares novos, conhecer Características/cultura local e conceitos relacionados. Importante notar que pessoas em Trajetos a trabalho também apontaram esporadicamente algumas dessas características como sendo importantes, mas poucos entrevistados relacionaram esses fatores aos Critérios para a escolha do caminho. Para escolher o caminho, as pessoas em Trajetos a trabalho salientaram fatores como o Fluxo do trânsito, da Distância do trajeto e de serem Caminhos mais simples ou Caminhos mais movimentados, "para evitar riscos" [E1]. Essa diferença pode ser observada nos trechos a seguir:

Trajetos a lazer:

"A passeio são as atrações turísticas, né. Cada dia você faz um caminho pra chegar em um lugar diferente." [E1]

"Por exemplo, lá em [cidade turística de litoral], as vezes que eu andei por lá pra ir conhecer os lugares, eu procurava sempre ir por onde tinha mais lugares interessantes pra eu conhecer né. Tanto a praia quanto os pontos turísticos de lá.” [E7]

"Ah, eu procuro paisagens, né. Imagens bonitas, pode ser tanto em cidade como floresta, né, você ver uma colina, uma paisagem de campo, uma paisagem de cidade, alguns prédios. Cada um tem seu tipo de beleza." [E5]

Trajetos a trabalho:

"Podem ter vários fatores aí influenciando, né. A questão da distância, do quão otimizado você pode fazer o trajeto. Como que é a questão do fluxo [do trânsito]. Se for uma coisa que você tem que ir em horários não tão comuns ou pelo menos um pouco mais restritos, é ver a questão de segurança também. [...]" [E6] 
A despeito da preocupação com os fatores convencionais do trajeto, quando questionados sobre a Flexibilidade do trajeto e os Critérios para a escolha do trajeto, embora pessoas em Trajetos a trabalho tenham destacado a importância de fazer Sempre o mesmo caminho e afirmado escolher Caminhos mais simples ou Caminhos mais movimentados, por razões de Segurança e Tempo, elas também apontaram para o interesse de conhecer os arredores, como pode ser observado nos trechos abaixo:

"No trabalho, [procuro conhecer] sim, perto do hotel, geralmente, que é onde a gente tem oportunidade." [E1].

"Ali próximo ao hotel, eu procuro [conhecer]. Eu não abro muito o raio não.” [E6]

“Geralmente não dá tempo, mas gostaria sim, de conhecer tudo." [E2]

Nesses casos, a Oportunidade foi mencionada como uma característica importante. Além de Explorar os arredores do hotel, pessoas que fazem Trajetos a trabalho apontaram a Alimentação como um fator que colabora com a Flexibilidade para conhecer os arredores. Por exemplo, a entrevistada [E1] afirmou que quando está a trabalho, aproveita para conhecer os arredores quando sai para comer, "porque a única coisa que a gente faz além de trabalhar é comer" [E1].

Outra característica interessante dos Trajetos não rotineiros foi o Des/interesse por locais familiares. Por familiares, entende-se locais não rotineiros, porém que o indivíduo tem a sensação de ser um local conhecido. Por exemplo, bairros ou ruas desconhecidas na sua própria cidade. Alguns entrevistados afirmaram que quando precisam realizar Atividades pessoais esporádica, não observam o trajeto, ainda que seja a primeira vez que passa pelo local. Isso pode ser visto no trecho a seguir:

"Então daí também depende do local onde eu estou [...]. Por exemplo, em [cidade em que moro] mesmo, quando eu preciso ir em um lugar onde eu não vou com tanta frequência, eu quase nem reparo nas coisas assim em volta [...]. Agora quando eu fui pra [cidade turística][por motivo profissional] eu já reparava tudo, muito mais, né. Eu olhava tudo." [E7]

Entretanto, o entrevistado E3 afirmou ser "bem observador" e reconhecer "pelo menos as paisagens" dos locais por onde transita. Essa contradição mostra que o perfil individual é relevante.

Nos Trajetos a lazer, o tempo deixa de ser um aspecto restritivo. A inversão da relação com o tempo faz com que as pessoas estejam mais dispostas a observar. As pessoas se mostraram flexíveis a fazer Caminhos diferentes (nenhum entrevistado mencionou fazer sempre o mesmo caminho), utilizando como Critério para escolha do caminho conceitos como Visitar atrações turísticas, Curiosidade, Sinalização e até mesmo uma escolha Aleatória, como a citação abaixo:

"[Escolho o caminho] Aleatoriamente. Nem que seja o mais longo. Porque dai eu vou acabar vendo outras coisas." [E4]

Nesse tipo de trajeto, as pessoas disseram que procuram Conhecer bem os arredores, têm pré-disposição para Experimentar atividades novas e fazem caminhos diferentes com o objetivo de Conhecer lugares novos. Em locais históricos ou 
turísticos, os caminhos mais interessantes são os que possibilitam Visitar as atrações turísticas. Esses conceitos podem ser observados nas citações a seguir:

"Mas assim, na questão de estar lá em [cidade turística], se fosse um caminho mais distante, eu procuraria fazer trajetos diferentes, pra conhecer lugares diferentes." [E7]

"Se tiver já mais uma flexibilidade maior de tempo ou de dias, e também talvez se tiver alguma outra motivação, tipo, alguém comentar alguma coisa assim 'ah, se você mudar o caminho ou se for por esse outro caminho tem alguma coisa interessante pra se conhecer ou pra se ver', isso de repente pode me motivar a fazer algum trajeto alternativo. " [E6]

"Então, é mais pra conhecer mais lugar, pra ver se identifica com algum... alguma paisagem. Procuro encontrar um lugar que me faça sentir bem, né. Isso que me atrai. " [E5]

É importante observar pelas citações que a novidade é um conceito relevante para a definição de interesse. De maneira geral, o interesse ou preferência de um indivíduo é definido pela escolha de algo que ele já conhece e lhe agrada. Entretanto, quando estão em Trajetos a lazer, as pessoas demonstraram fazer escolhas a despeito dos seus interesses. Isso foi especialmente observado nos contextos em que o entrevistado descreveu o Trajeto não rotineiro como uma Oportunidade (por exemplo, quando estavam em um local distante de seu local de moradia), o que fica evidente no trecho a seguir:

"[Faço caminhos diferentes] Pra ver se tem alguma coisa legal! Porque daí eu não sei se eu vou passar lá de novo! Vai que tem alguma coisa legal!” [E4]

Em decorrência disso, as Atividades de lazer e Turísticas mencionadas foram as mais variadas, como simplesmente Sair de casa, Experimentar a culinária local, Visitar bares, Restaurantes, Lojas, Atrações turísticas, entre outros. As citações a seguir são exemplos dessas atividades:

"Quando eu estou de férias: ah, dai [eu me desloco] pra beber, pra tomar sol, pra passear, pra tirar foto, pra.... risos” [E1]

"Agora quando você está passeando, você às vezes... sair de casa é o objetivo. Então você não vai com pressa, você está andando. [...] Você não está nem aí com o resto, você está ali só mesmo curtindo o lugar né." [E3]

Quando se trata de viagens, a diferença de perfil de deslocamento de acordo com o tipo do trajeto ocorre até mesmo na escolha do meio de transporte. Primeiramente, é fato que a escolha do meio de transporte da viagem pode justificar a utilização de meios de transporte alternativos no destino. Por exemplo, pessoas que viajam de avião, recorrem a táxis e ônibus no destino, o que não acontece com pessoas que viajam com carro próprio. No caso dos Trajetos a trabalho o Táxi foi mencionado como meio de transporte. Já as pessoas em Trajetos a lazer disseram utilizar Carro alugado, Ônibus e até mesmo caminhar A pé. Foi evidenciado também a pré-disposição dos indivíduos de utilizar meios de transporte mais lentos quando estão em Trajetos de lazer.

"E geralmente é de carro. Às vezes a pé se for próximo, mas senão, é de carro. Olha quando você viaja de avião, ai vai de ônibus, né [...] " [E3] 
Além disso, a questão do Custo apareceu uma única vez, relacionados a Trajetos a trabalho, quando o entrevistado afirmou utilizar o Táxi porque o custo com transporte era pago pelo empregador.

A Segurança também foi mencionada por pessoas em Trajeto não rotineiro como uma característica relevante para a escolha do caminho:

"A trabalho eu faço sempre o mesmo [trajeto] e procuro o mais movimentado, por não conhecer, pra evitar riscos. " [E1]

"Eu procuro usar o caminho que eu tenho certeza que dá certo, né." [E5]

Finalmente, a análise destacou que especificamente para Trajetos não rotineiros, tanto para atividades de lazer quanto para trabalho ou atividades pessoais esporádicas, as pessoas usualmente buscam informações sobre o trajeto antes de escolher. As pessoas disseram Perguntar a conhecidos ou Procurar em um mapa o melhor caminho a seguir. Esses conceitos são exemplificados nos trechos abaixo:

"Se você tem alguém que você conhece e que já foi, você vai perguntar quais são os lugares legais. A gente usa muito o [site de viagens e destinos] como foco de informação, muito mesmo, pra descobrir tudo, onde abastecer, onde visitar, onde comer, onde se hospedar, enfim, tudo. " [E1]

Especificamente com relação ao mapa, um dos entrevistados ressaltou o aspecto negativo da característica estática dos mapas, como pode ser observado a seguir:

"Distância do trajeto né. Porque você olha no mapa, né, parece que é tudo seguro. Mas às vezes você tá num caminho, dai você não acha seguro. Mas quando eu procuro pelo mapa é pela distância percorrida e não pela segurança da via." [E5]

\subsection{Trajetos rotineiros}

As categorias, subcategorias e códigos identificados para Trajetos rotineiros podem ser encontrados na Tabela 3. Quando analisando as respostas relacionadas a Trajetos rotineiros, pode-se concluir que por rotina entende-se, primariamente, Atividades profissionais (trabalho e estudo). Exceção a essa regra foi a entrevistada E2 cuja profissão é organizar excursões turísticas. Embora ela considere as viagens como seu trabalho, é profissional autônoma e organiza excursões sob demanda. Sendo assim, quando questionada sobre sua rotina, ela afirmou "Me desloco muito pouco. Saio para igreja, banco, visitar família." [E2], o que demonstra que ela desconsiderou suas viagens como parte de sua rotina. Além disso, as pessoas consideraram como rotineiras atividades pessoais (religiosas, sociais, domésticas e físicas) e alimentação. Outras atividades rotineiras mencionadas estão relacionadas à Atividades domésticas (como fazer compras), Atividades religiosas e à Atividades físicas (como natação, pilates e academia).

Quando o foco é direcionado à questão de pesquisa " $O$ que as pessoas consideram interessante para a escolha do trajeto durante o deslocamento urbano?" a análise mostrou que o conceito chave é, de fato, o Tempo. Todas as Características importantes do trajeto possuíam alguma relação com a redução do tempo do trajeto. 
Tabela 3: Categorias, subcategorias e códigos identificados para Trajetos rotineiros

\begin{tabular}{|c|c|c|}
\hline Categorias & Subcategorias & Códigos \\
\hline \multirow{4}{*}{ Motivo do deslocamento } & Atividades pessoais & Alimentação, Visitar família, Médico \\
\hline & Atividades domésticas & Banco, Compras/Comércio \\
\hline & Atividades profissionais & Trabalho, Estudo \\
\hline & Atividades físicas & Natação, Pilates, Corrida, Ciclismo, Academia \\
\hline Meio de transporte & - & Carro, A pé, Moto, Bicicleta, Ônibus \\
\hline $\begin{array}{c}\text { Critério para escolha do } \\
\text { meio de transporte }\end{array}$ & - & Tempo, Volumes para carga, Praticidade, \\
\hline \multirow[t]{2}{*}{ Flexibilidade do trajeto } & $\begin{array}{l}\text { Sempre o mesmo } \\
\text { caminho }\end{array}$ & Falta de opção de trajeto, Hábito, \\
\hline & Caminhos diferentes & Otimização da rotina \\
\hline \multirow[b]{2}{*}{$\begin{array}{c}\text { Características } \\
\text { importantes do trajeto }\end{array}$} & Alimentação & Alimentação saudável \\
\hline & Características das vias & $\begin{array}{l}\text { Facilidade de acesso a bairro, Exclusividade de veículos } \\
\text { leves, Fluxo do trânsito, Sincronismo dos semáforos, } \\
\text { Prioridade em determinada direção das vias, Sinalização, } \\
\text { Bom para caminhada }\end{array}$ \\
\hline \multirow{3}{*}{$\begin{array}{l}\text { Critério para escolha do } \\
\text { caminho }\end{array}$} & Características do local & Relevo \\
\hline & Tempo & Tempo, Otimização da rotina, Distância \\
\hline & - & Aleatório, Disposição física \\
\hline $\begin{array}{c}\text { Flexibilidade para } \\
\text { conhecer os arredores }\end{array}$ & Caminhos diferentes & $\begin{array}{l}\text { Pontos de referência, Alimentação, Otimização da rotina, } \\
\text { Observação de paisagens/locais, Buscar por utilidades do } \\
\text { dia-a-dia, Curiosidade, Explorar ruas novas, Desinteresse em } \\
\text { locais familiares }\end{array}$ \\
\hline
\end{tabular}

Ademais, alguns Critérios para a escolha do trajeto também circundam a questão do Tempo. O tempo foi mencionado explicitamente como um critério, por exemplo, no excerto "É, eu acho que o princípio que norteia o caminho é o tempo que você leva pra sair de um lugar e chegar no outro. Isso é o mais importante. O maior objetivo é chegar mais rápido no lugar que você planejou." [E3].

Em outros casos, o Tempo é associado a outros critérios, como Fluxo do trânsito e o Relevo. Por exemplo, o entrevistado E5 afirmou fazer um trajeto mais longo rotineiramente, porque utiliza bicicleta e o relevo da cidade faz o caminho mais longo ser mais rápido.

"Então, [eu uso] bicicleta, [...] na maioria das vezes eu faço o mesmo caminho, não mudo muito não. Porque tem o relevo da cidade, né [...] Eu escolho uma [rua] que parece mais plana pra eu tentar ir em cima da bicicleta, pra ir mais rápido. [...] Se saísse minha moto do consórcio eu com certeza faria outro caminho. [...] Porque dai eu ia mais direto, né? Seria o menor caminho pra ir. " [E5]

O trecho anterior mostra a maior relevância do Tempo com relação à Distância do percurso. Em outras características, isso também foi observado. O Tempo norteia a escolha do meio de transporte, a escolha do caminho, a flexibilidade para fazer trajetos diferentes. Por exemplo, a entrevistada E6 afirmou fazer sempre o mesmo caminho, porque "agora a coisa já está mais ou menos esquematizada." [E6]. Entretanto, ela afirma que esporadicamente tenta caminhos alternativos, para "explorar alguma rua nova que foi aberta ali no bairro". Quando questionada sobre os interesses que a levam a explorar, a entrevistada retomou a questão do tempo:

"Por exemplo, como é que está o fluxo de trânsito, a sinalização. Porque às vezes esses caminhos alternativos podem se tornar mais extensos, mas devido à redução no fluxo de trânsito, a gente pode gastar menos tempo." [E6] 
Alguns entrevistados mencionaram a Falta de opções de trajeto em situações rotineiras. Essa característica está supostamente relacionada ao perfil dos entrevistados, que ou utiliza rodovia para chegar ao trabalho, ou reside muito próximo dos seus destinos rotineiros. Nestes casos, as pessoas afirmaram conhecer bem os arredores do destino e não prestar atenção nas características do trajeto.

“É, eu não lembro nome de rua, mas eu conheço tudo." [E5]

Por outro lado, a análise mostrou que as pessoas em Trajetos rotineiros têm menos interesse em observar o trajeto, o que deve supostamente ocorrer pelo Desinteresse em locais familiares. Nenhum dos entrevistados mencionou, como Características importantes do trajeto, conceitos relacionados às Características do local. Vale observar que todas as pessoas que disseram conhecer todas as localidades ao redor dos destinos rotineiros são moradoras de cidades pequenas (até $100 \mathrm{mil}$ habitantes) e vivem na mesma cidade há muitos anos. Essa característica de perfil pode ter sido determinante para este fator. Os demais entrevistados afirmaram que as Características importantes do trajeto e a Flexibilidade para conhecer os arredores são relacionadas a Pontos de referência ou Buscar utilidades do dia-a-dia, como mercado, posto de gasolina, pet shop, restaurantes ou igrejas.

“[Conheço] só as principais referências, não exploro o lugar.” [E1]

"Olha, o que me chama a atenção são coisas do meu dia-a-dia. Posto de gasolina, mercado, farmácia, pet shop, às vezes a gente está... tem dias que a gente está com mais pressa e não repara muito nas coisas que estão na rua, mas às vezes você está passando por aquela rua pela milésima vez, ai você fala assim 'nossa, ali tem uma igreja!'. Nunca tinha visto que tinha uma igreja ali. A gente acaba descobrindo as coisas assim, com o passar do tempo, né. Mas, às vezes tem outro prédio assim que a gente não presta muita atenção." [E3]

A imersão das pessoas nas questões do trabalho e responsabilidades, bloqueando a atenção a outros aspectos interessantes do trajeto, foi curiosamente observado na entrevista com a agente de viagens. Como foi anteriormente discutido, ela não considerou suas excursões como trajetos rotineiros, apesar de ser seu trabalho. Entretanto, quando questionada sobre as Características importantes dos trajetos, ela não mencionou as Atrações turísticas dos locais que visita. Pelo contrário, ela demonstrou preocupação com a Segurança e disse que a o mais importante no caminho é ser Bom para caminhada, como pode ser observado nas citações abaixo:

"Como sempre tenho pessoas idosas sempre peço um caminho que não seja dificil e cansativo. Seriam os melhores caminhos. [...] Como sempre tenho um guia que acompanha em viagens vou onde eles me levam. Geralmente não conheço o caminho. Mesmo sendo a mesma viagem duas ou três vezes, sigo eles. Meu trabalho. Não viajo sozinha nunca." [E2]

Outros conceitos apontados pelos respondentes foram a necessidade de Compras/Comércio e a Alimentação. Especificamente sobre a Alimentação, opções diferentes de podem fazer com que as pessoas optem por outro trajeto. A citação a seguir aponta para essa questão:

"Mais [importante é] restaurante. Acho que alimentação de um modo geral, das coisas mais simples. Por exemplo, coisas que faltam aqui em 
[cidade que mora], opções de alimentação saudável. Se tivesse um lugar assim eu procuraria." [E1]

\section{Discussão}

A análise das entrevistas forneceu diversos indícios de aspectos que podem ser considerados interessantes para pessoas que estão se deslocando pelas cidades. $\mathrm{O}$ primeiro resultado importante foi a confirmação da diferença entre os perfis de deslocamento de pessoas em situações rotineiras daquelas em situações não rotineiras. Mais do que isso, a análise mostrou diferenças significativas no interesse de pessoas em trajetos não rotineiros a trabalho e a lazer. Abou-Zeid et al. (2008) sugere que quando pessoas estão em sua rotina, elas não consideram completamente sua "felicidade com a viagem", o que pode explicar as diferenças no perfil de deslocamento. As pessoas que estão a lazer, ou que estão em lugares diferentes, ficam mais suscetíveis às influências que as características do trajeto podem oferecer, como as diferentes paisagens, estabelecimentos e atividades locais.

Para pessoas em trajetos não rotineiros, um aspecto importante para a recomendação de trajetos personalizados é explorar a Oportunidade. Especialmente para os trajetos a trabalho, como o tempo de deslocamento e os horários são fatores restritivos, as pessoas disseram conhecer os lugares em que tem oportunidade (próximo ao hotel, próximo a restaurantes). Sistemas de recomendação de trajetos poderiam utilizar recomendações de pontos de interesses próximos para sugerir um trajeto alternativo que explore as características locais (pontos turísticos, paisagens urbanas/rurais, cultura). Neste caso, embora o interesse dos indivíduos precise ser considerado, a análise mostrou que as pessoas têm curiosidade de conhecer "coisas novas" ou "diferentes" que caracterizem o local que visitam. Portanto, essa recomendação deveria ser realizada a despeito dos interesses do indivíduo. A recomendação não deveria impedir que o usuário experimente algo novo [Ballatore and Bertolotto 2015]. Uma maneira de selecionar os locais de interesse próximos poderia ser através do histórico de visitações e similaridade de perfis (utilizando algoritmos de filtragem colaborativa), considerando suas restrições de tempo, segurança e disponibilidade de meio de transporte.

Para pessoas em trajetos a lazer, a questão do tempo é menos importante, o que pode ser destacado pelo fato de as pessoas às vezes optarem por meios de transporte mais lentos do que os que usam em sua rotina. Sistemas de Recomendação de trajetos personalizados poderiam melhorar a experiência do usuário durante o seu passeio criando trajetos semelhantes aos propostos acima (para trajetos não rotineiros de trabalho), porém com maior flexibilidade de tempo e opções de meio de transporte (por exemplo, poderia sugerir uma caminhada por alguma rua específica). As questões de segurança continuam sendo importantes. As recomendações poderiam incluir contextos como a quantidade de dias que o usuário tem disponível no lugar, o tempo que as pessoas costumeiramente demoram em cada ponto de interesse (que pode ser obtido com histórico de visitação), considerar a chegada em restaurantes próximo dos horários de refeições, além de sugerir trajetos cíclicos, que retornem ao ponto de partida no final do percurso, melhorando o aproveitamento da viagem.

Outro conceito importante destacado pela análise foi o fato de as pessoas habitualmente Perguntarem a conhecidos sobre os locais não rotineiros. Técnicas de 
crowdsoucing poderiam ser utilizadas para apoiar a recomendação. Utilizar contatos em redes sociais para identificar pessoas conhecidas e sugerir pessoas que já visitaram o destino também são opções que podem ser exploradas.

Com relação aos trajetos rotineiros, os resultados mostram algo esperado: o impacto do tempo nas escolhas do trajeto. Ferramentas comerciais de recomendação de rotas, em geral, focam neste aspecto. Entretanto, os resultados mostram também a dificuldade em observar outros aspectos do trajeto. A pesquisa apresentada em [AbouZeid et al. 2008] mostra que uma mudança temporária no comportamento deve ser efetiva para induzir uma modificação comportamental ou minimamente afetar a escolha das pessoas. Por exemplo, a entrevistada E1, apesar de ter apontado a alimentação próxima ao destino como uma forma de otimização da rotina, disse que procuraria por lugares que oferecessem uma "opção de alimentação saudável". Talvez oferecer uma opção de trajeto com alimentação saudável possa ser a "janela da mudança" que a entrevistada precisa para reconsiderar sua escolha de caminho. Neste caso, é importante que sejam realizadas novas pesquisas direcionadas especificamente para pessoas em trajetos rotineiros, sugerindo pequenas variações em seus trajetos e verificando seu comportamento com relação às mudanças. Uma abordagem poderia utilizar os interesses das pessoas extraídos de redes sociais para sugerir novos cenários que façam com que a pessoa reflita sobre seu trajeto e avaliar se essa reflexão pode gerar novas escolhas que não sejam exatamente influenciadas apenas pelo tempo do trajeto.

\section{Limitações}

Como passo inicial desta pesquisa, foram entrevistados sete sujeitos. Com apenas essas entrevistas não é possível afirmar que se alcançou a saturação teórica, conforme pregado pelas Grounded Theory. Para os Trajetos não rotineiros, é necessário que se defina um número maior de perfis possíveis, já que a diferença entre perfis pode impactar no surgimento de novos conceitos. Entretanto, para os Trajetos rotineiros, apesar das diferenças de perfis dos entrevistados, a pesquisa chegou muito próxima da saturação teórica. Isso se deve ao instrumento de pesquisa utilizado. Conforme discutido na Seção 6, as entrevistas mostraram que, quando convidadas a raciocinar sobre seus interesses no trajeto, as pessoas em Trajetos rotineiros têm dificuldades em observar aspectos que não estejam relacionados ao Tempo. Sendo assim, utilizando o instrumento de pesquisa apresentado neste artigo, algumas poucas entrevistas seriam necessárias para chegar à saturação teórica. Todavia, é necessário criar novos instrumentos que auxiliem pessoas em trajetos rotineiros a considerar outros aspectos, mais relacionados à satisfação pessoal, conforto e felicidade no trajeto. Mais entrevistas estão planejadas a fim de explorar este e outros dos pontos levantados durante a discussão.

Além disso, pode-se dizer que existe um potencial viés de seleção dos participantes, já que os perfis analisados podem não representar todos os possíveis perfis de pessoas. Isso se justifica pelo caráter exploratório preliminar desta pesquisa. Como para esta etapa da pesquisa seria inviável ter uma amostra que represente toda a população e, visando aliviar o problema, definiu-se um escopo específico e características que foram consideradas inicialmente relevantes. Dentro dos perfis definidos, foram convidadas pessoas que se encaixassem nas características. 
Outra potencial ameaça à validade está relacionada à subjetividade da classificação dos dados. A pesquisa utilizou procedimentos de Grounded Theory que, para mitigar essa ameaça (comum a métodos qualitativos, com caráter interpretativistas), prega que toda a análise seja fundamentada nos dados coletados. Além disso, houve discussão sobre o processo de análise com um especialista em Grounded Theory durante a realização das etapas do método.

\section{Conclusão}

Neste trabalho foi investigado "O que as pessoas consideram interessante para a escolha do trajeto durante o deslocamento urbano?". Para responder à questão, foram realizadas entrevistas e os dados qualitativos coletados foram analisados usando codificação aberta e axial. Os resultados, resumidos nas Tabelas 1, 2 e 3 da Seção 4, mostraram que quando não influenciadas pelo tempo, as pessoas observam paisagens, pontos de interesse, tem disposição de experimentar coisas novas (culinária, atividades) e que, além de consultar mapas, as opiniões de outras pessoas são importantes fontes de informação no momento de escolher um caminho ou destino desconhecido. Além disso, foi possível observar que as pessoas em sua rotina têm dificuldade em observar aspectos que não sejam relacionados ao tempo de deslocamento.

Este trabalho consiste em uma pesquisa preliminar de caráter exploratório, que visa fornecer subsídios para as próximas etapas desta pesquisa. Novas pesquisas precisam ser realizadas para confirmar os resultados obtidos. Como potencial contribuição deste trabalho tem-se que, para sugerir trajetos personalizados, as informações sobre os interesses individuais e sociais são aspectos que podem ser obtidos por meio de informações disponíveis em redes sociais, em sugestões de contatos e de outras pessoas com similaridades de perfil. É necessário estudar o uso de algoritmos de filtragem colaborativa e informações de contexto para relacionar essas informações aos aspectos dinâmicos, como atividade que o usuário está realizando, meio de transporte, entre outros. Com isso, espera-se que seja possível utilizar os interesses pessoais e sociais dos indivíduos na recomendação de trajetos, melhorando sua experiência no deslocamento urbano.

\section{Agradecimento}

A autora Ana Paula Chaves agradece à Fundação Araucária e à Secretaria de Estado da Ciência, Tecnologia e Ensino Superior do Paraná (SETI), pelo apoio financeiro.

\section{Referências}

Abou-Zeid, M., Ben-Akiva, M. and Bierlaire, M. (2008). "Happiness and travel behavior modification". In European Transport Conference.

Adomavicius, G. and Tuzhilin, A. (2011). "Context-aware recommender systems". Recommender systems handbook. Springer. p. 217-253.

Ballatore, A. and Bertolotto, M. (nov 2015). "Personalizing Maps". Communications of $A C M$, v. 58, n. 12 , p. $68-74$.

Bao, J., Zheng, Y. and Mokbel, M. F. (2012). "Location-based and Preference-aware Recommendation Using Sparse Geo-social Networking Data". In Proceedings of the 
20th International Conference on Advances in Geographic Information Systems. , SIGSPATIAL' '12. ACM.

Bao, J., Zheng, Y., Wilkie, D. and Mokbel, M. (2015). "Recommendations in locationbased social networks: a survey". GeoInformatica, v. 19, n. 3, p. 525-565.

Campigotto, P., Rudloff, C., Leodolter, M. and Bauer, D. (2016). "Personalized and situation-aware multimodal route recommendations: the FAVOUR algorithm". CoRR, v. abs/1602.09076.

Cassiani, S. H. D. B., Caliri, M. H. L. and Pelá, N. T. R. (1996). A teoria fundamentada nos dados como abordagem da pesquisa interpretativa. Revista Latino-Americana de Enfermagem, v. 4, p. 75-88.

Chen, C., Zhang, D., Guo, B., et al. (2015). "TripPlanner: Personalized Trip Planning Leveraging Heterogeneous Crowdsourced Digital Footprints”. IEEE Transactions on Intelligent Transportation Systems, v. 16, n. 3, p. 1259-1273.

Corbin, J. and Strauss, A. (2014). "Basics of qualitative research: Techniques and procedures for developing grounded theory". Sage publications.

Kurashima, T., Iwata, T., Irie, G. and Fujimura, K. (2012). "Travel route recommendation using geotagged photos". Knowledge and Information Systems, v. 37 , n. 1, p. $37-60$.

Pires, C. S., Aguiar, M. S. De and Ferreira, P. R. (2015). "Mobile ACORoute-Route Recommendation Based on Communication by Pheromones". Polibits, n. 51, p. $27-$ 32 .

Su, H., Zheng, K., Huang, J., et al. (2014). "Crowdplanner: A crowd-based route recommendation system". In Data Engineering (ICDE), 2014 IEEE 30th International Conference on. . IEEE.

Tsai, C. Y. and Lai, B. H. (2013). "A Customized Visiting Route Service under RFID Environment". In Computer Software and Applications Conference Workshops (COMPSACW), 2013 IEEE 37th Annual.

Tsai, C.-Y. and Chung, S.-H. (2012). "A personalized route recommendation service for theme parks using $\{$ RFID $\}$ information and tourist behavior". Decision Support Systems, v. 52, n. 2, p. 514-527.

Yang, B., Guo, C., Ma, Y. and Jensen, C. S. (2015). "Toward Personalized, Contextaware Routing". The VLDB Journal, v. 24, n. 2, p. 297-318. 